\title{
Identification of Allergens in the Box Jellyfish Chironex yamaguchii That Cause Sting Dermatitis
}

\author{
Takumi Horiike $^{a}$ Hiroshi Nagai $^{a} \quad$ Seiichi Kitani ${ }^{b}$ \\ ${ }^{a}$ Department of Ocean Sciences, and ${ }^{b}$ Health Service Center, Graduate School of Marine Science and Technology, \\ Tokyo University of Marine Science and Technology, Tokyo, Japan
}

\section{Key Words}

Specific allergen - Box jellyfish dermatitis . Chironex

yamaguchii $\cdot$ Nematocyst . Venom immune reaction

\begin{abstract}
Background: Jellyfish stings cause painful, papular-urticarial eruptions due to the immediate allergic, acute toxic and persistent inflammatory responses. In spite of many marine accidents and their economic impact, modes of first-aid treatment remain conventional and specific allergen and medical treatment are not yet available. The purpose of this study was to define the specific allergen of the box jellyfish Chironex yamaguchii and to study the precise mechanism of the resulting dermatitis. Methods: We comprehensively studied the immunoglobulin-binding molecules from the box jellyfish C. yamaguchii with a purification procedure and Western blotting, using sera from 1 patient and from several controls. Results: From the nematocyst wall and spine, we detected IgG-binding acidic glycoprotein (of 66 and $30 \mathrm{kDa}$ ) as determined by Western blot and ion-exchange chromatography. In addition, the 66-kDa protein was found to be an asparagine residue-coupled $\mathrm{N}$-linked glycoprotein and the epitope resided in the protein fraction. We found that CqTX-A, the major toxic protein of the nematocyst, is also a heat-stable
\end{abstract}

IgE-binding allergen. This was confirmed as a 45-kDa protein by Western blot from both nematocyst extracts and purified CqTX-A. Conclusions: The detection of these proteins may, in part, explain the combined immediate allergic-toxic and persistent allergic responses. Hopefully, our findings will lead to the development of specific venom immunotherapy for marine professional workers and tourists for jellyfishsting dermatitis and anaphylaxis.

(c) 2015 S. Karger AG, Basel

\section{Introduction}

The box jellyfish Chironex yamaguchii (also known as Chiropsalmus quadrigatus) inhabits the tropical Indo-Pacific region [1]. Envenomation of C. yamaguchii occurs in coastal areas from June to September, especially in Okinawa in the tropical region of Japan. The species is distinguished by the cube-shaped medusa, and is classified into Cubozoa (a so-called box jellyfish or sea wasp) of cnidarian. Box jellyfish stings, including those from C. yamaguchii, Chironex fleckeri and Carukia barnesi as well as the hydrozoan jellyfish Physalia physalis (Portuguese manof-war), can be fatal $[2,3]$. Contact with the jellyfish triggers the nematocysts (harpoon-shaped microscopic 


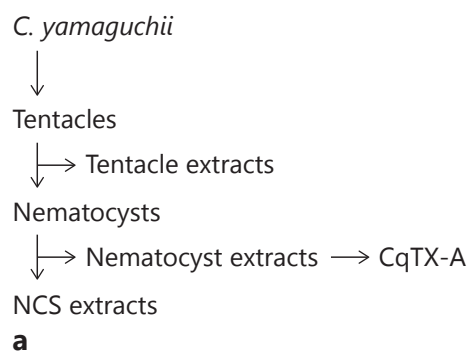

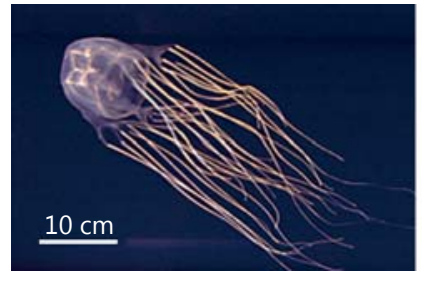

b Whole body

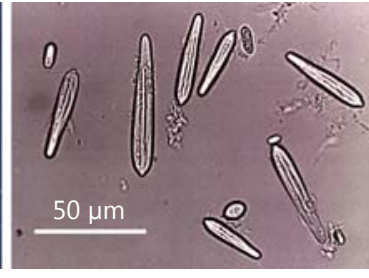

Nematocysts

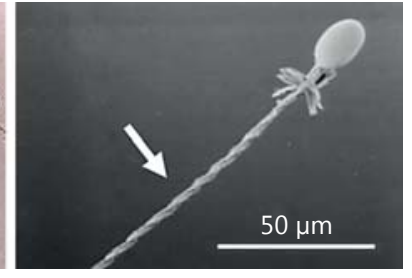

Discharging nematocyst
Fig. 1. Purification process from the box jellyfish C. yamaguchii. a Schematic diagram of the purification, described in Materials and Methods. b Functional anatomy of C. yamaguchii. The first photograph shows the whole body (the tentacles are 3-4 times lon- ger than the head). A microscopic image of nematocysts isolated from the tentacles is shown and also a scanning electron microscopic image of a nematocyst discharging the spine. mechanisms) that exist on the tentacles to inject venom into the victim's skin. A worldwide epidemiological survey recorded that there are 150 million cases of jellyfish stings a year [4]. In Okinawa, 103/132 jellyfish stings officially reported in 2013 were caused by C. yamaguchii [5].

Jellyfish stings cause painful, papular-urticarial eruptions due to immediate allergic, acute toxic and persistent inflammatory responses [6]. The most characteristic signs and symptoms are painful skin eruptions at the sting site. These acute lesions usually last for minutes to hours, and the rash is combined with urticaria. Further progression can lead to vesicles, hemorrhaging or necrotizing lesions. Delayed reactions such as pruritic urticarial lesions may relapse after 2-4 weeks [7]. Systemic reactions may occur and these often result in cardiovascular and respiratory failure, probably due to a combination of toxicity and anaphylaxis. It was assumed that these are allergic reactions, but the nature of the allergen(s) has not yet been elucidated [8]. In spite of the many accidents and the risk to fishery employees and marine tourists, no definite consensus exists for effective first-aid, clinical management or specific medical treatment.

Cnidarians have countless numbers of nematocysts on the surface of their tentacles. The nematocyst is specialized to inject venom into the victim. It is filled with other components such as protein toxins, inflammatory molecules, polypeptides and enzymes $[9,10]$. It also has a mechanical apparatus that encloses a folding spine, like a harpoon. The nematocyst capsule wall and spine (NCS) are made of hard tissues, formed by the strong binding of minicollagen and glycoprotein $[11,12]$. The nematocyst injects venom in response to physical and/or chemical stimulation [13]. A major protein toxin, CqTX-A, with a molecular weight of $45 \mathrm{kDa}$ has already been isolated from the venom of C. yamaguchii and the deduced amino acid sequence clarified [14]. CqTX-A exhibits potent hemolytic activity and crayfish-lethal toxicity [14]. A small amount of cytotoxic protein $(43 \mathrm{kDa})$ was found in the venom [15].

Recently, many allergens from marine organisms have been reported, such as in sea urchins and red soft coral $[16,17]$. The purpose of this study was to define the specific allergen of the box jellyfish C. yamaguchii and the precise mechanism of the resulting dermatitis. From our comprehensive investigation, starting with this species, we detected the IgG-binding acidic glycoprotein in the NCS, and identified CqTX-A, in the nematocyst, as the critical allergen and main toxic protein.

\section{Materials and Methods}

Collection of C. yamaguchii

The box jellyfish C. yamaguchii was captured and collected at Ginowan, Okinawa, Japan in the month of August. The tentacles were excised from the live specimen immediately after capture and frozen at $-30^{\circ} \mathrm{C}$. The remaining body was discarded. The purification process is charted in figure 1a.

\section{Preparation of Crude Extracts from Tentacles}

The frozen tentacles of C. yamaguchii were excised in $10 \mathrm{~mm}$ PBS (pH 7.0) using scissors, and were then sonicated with an ultrasonicator MUS-400 (EYELA, Tokyo Rikakikai Co., Tokyo, Japan). The obtained suspension was centrifuged at $10,000 \mathrm{~g}$ for 5 min. The supernatant was filtered with a $0.45-\mu \mathrm{m}$-disk filter (ADVANTEC, Toyo Roshi Kaisha, Tokyo, Japan). The filtrate was defined as the tentacle extracts (fig. 1a). 
Preparation of Isolated Nematocysts

Nematocysts (wet weight: $15 \mathrm{~g}$ ) were isolated from the frozen tentacles of C. yamaguchii (fig. 1a) as described previously [18]. The frozen tentacles (wet weight: $100 \mathrm{~g}$ ) were autolyzed in $1.0 \mathrm{M}$ sodium citrate solution $(200 \mathrm{ml})$ for 5 days at $4{ }^{\circ} \mathrm{C}$. The autolyzed suspension was filtered through fine-mesh nylon netting. The filtrate was allowed to settle in a beaker for $3 \mathrm{~h}$ at $4^{\circ} \mathrm{C}$. The supernatant was then removed by decanting and the nematocysts were washed with $1.0 \mathrm{M}$ of sodium citrate solution for isolation.

\section{Preparation of Nematocyst Extracts}

Nematocyst extracts were prepared by bead mill homogenization as described by Carrette and Seymour [19]. The nematocysts were washed with $10 \mathrm{~mm}$ phosphate buffer ( $\mathrm{pH}$ 6.0), and then resuspended in the same buffer and ruptured using a Mini-Beadbeater (BioSpec Products, Bartlesville, Okla., USA) and 0.5-mm glass beads. Disruption of the nematocyst was monitored microscopically. The suspension was then centrifuged at $10,000 \mathrm{~g}$ for $5 \mathrm{~min}$ and the supernatant was filtered through a 0.45 - $\mu \mathrm{m}$-disk filter. The filtrates were considered as nematocyst extracts (fig. 1a).

\section{Isolation of CqTX-A from C. yamaguchii}

The isolation of CqTX-A, a main protein toxin of C. yamaguchii, was conducted as described [14]. Nematocyst extracts (7.0 g) were put on a cation-exchange HPLC, TSK-GEL CM$5 \mathrm{PW}$ column $(7.5 \times 75 \mathrm{~mm}, 0.5 \mathrm{ml} / \mathrm{min}$; TOSOH, Tokyo, Japan $)$ which had been equilibrated with $10 \mathrm{~mm}$ phosphate buffer containing $0.3 \mathrm{M} \mathrm{NaCl}(\mathrm{pH} 6.0)$, and the column was then washed with $10 \mathrm{~mm}$ phosphate buffer ( $\mathrm{pH}$ 6.0). The adsorbed components, which included CqTX-A, were eluted with a gradient solvent system $(0-0.7 \mathrm{M} \mathrm{NaCl}$ for $0-90 \mathrm{~min})$. The toxicity was checked by means of a hemolytic activity test as described below. The column-adsorbed toxic fraction was concentrated using a cation-exchange HPLC, TSK-GEL CM-5PW column [14]. The concentrated active fraction was applied to a gel permeation HPLC, Superdex 75 column $(15 \times 280 \mathrm{~mm}, 1.0 \mathrm{ml} / \mathrm{min}$; Amersham Pharmacia Biotech/GE Healthcare UK, Chalfont St Giles, UK), which had been equilibrated with $0.5 \mathrm{M} \mathrm{NaCl}$ and $10 \mathrm{mM}$ phosphate buffer ( $\mathrm{pH}$ 7.0). Finally, CqTX-A was isolated as an active molecule (fig. 1a). HPLC elution was monitored with a UV detector at $210 \mathrm{~nm}$. The separation of each fraction was monitored by SDS-PAGE. Protein concentration of the sample was measured using a BCA protein assay (Pierce/Thermo Fisher Scientific, Waltham, Mass., USA) following the manufacturer's instructions. CqTX-A was deactivated by boiling for $5 \mathrm{~min}$ for the comparison study of intact and thermally deactivated CqTX-A.

\section{Preparation of NCS Extracts}

From the nematocyst residues obtained during the preparation of the nematocyst extracts, the proteinaceous components of the capsule and spine were extracted by heating at $60^{\circ} \mathrm{C}$ in $0.8 \mathrm{M}$ 2 -mercaptoethanol for $30 \mathrm{~min}$. The extracts were centrifuged at $10,000 \mathrm{~g}$ for $30 \mathrm{~min}$, and the supernatants were recovered and filtered through a $0.45-\mu \mathrm{m}$-disk filter. The filtrates were used as NCS extracts (fig. 1a).

\section{Hemolytic Activity Test}

A hemolytic activity test was conducted as described previously [20]. Sample solutions $(50 \mu \mathrm{l})$ were incubated in microtubes with a $400-\mu \mathrm{l}$ suspension of $0.8 \%$ sheep red blood cells (Nippon Biotest
Lab., Tokyo, Japan) in $10 \mathrm{mM}$ PBS at $37^{\circ} \mathrm{C}$ for $2 \mathrm{~h}$. Cell suspensions were centrifuged at $2,000 \mathrm{~g}$ for $10 \mathrm{~min}$. The concentration of hemoglobin released into supernatant was measured at $570 \mathrm{~nm}$ with a microtiter plate reader (Model 550; Bio-Rad Lab., Hercules, Calif., USA). In this assay, 1 unit was defined as the dose which caused $50 \%$ hemolysis.

\section{Ion-Exchange Chromatography on NCS Extracts}

To characterize NCS extracts, ion-exchange chromatography using an anion or cation column was performed. For anion-exchange chromatography, NCS extracts $(20 \mathrm{mg}$ ) were loaded to HiTrap-DEAE (GE Healthcare) chromatography, which had been equilibrated with $10 \mathrm{mM}$ of phosphate buffer containing $0.3 \mathrm{M}$ $\mathrm{NaCl}$ (pH 7.5). The column was then washed with $10 \mathrm{~mm}$ phosphate buffer ( $\mathrm{pH}$ 7.5). The adsorbed fraction was eluted with 10 $\mathrm{mM}$ phosphate buffer containing $1.0 \mathrm{M} \mathrm{NaCl}(\mathrm{pH} 7.5)$ without a concentration gradient, in order to get a higher yield. For cationexchange chromatography, the same methods were applied as for anion-exchange except that a HiTrap-CM (GE Healthcare) column and $10 \mathrm{mM}$ of phosphate buffer ( $\mathrm{pH}$ 6.0) were used instead. Adsorbed and nonadsorbed fractions were obtained from both anion- and cation-exchange chromatography, followed by SDSPAGE and Western blotting.

\section{Western Blot}

Sample proteins were analyzed by $10 \%$ SDS-PAGE under a condition of reducing by 2 -mercaptoethanol or a nonreducing condition. Proteins in the gels were transferred onto a PVDF membrane (Bio-Rad) in a Mini Trans-Blot (Bio-Rad) for $4 \mathrm{~h}$ at $60 \mathrm{~V}$. After transfer, the PVDF membrane was blocked with $2.5 \%$ skim milk in Tris-buffered saline ( $\mathrm{pH} 7.6)$ containing $0.1 \%$ Tween 20 (TBS-T) for $1 \mathrm{~h}$ at room temperature. The membrane was incubated for $1 \mathrm{~h}$ at room temperature with primary antibody (1:2,500 dilutions) in TBS-T. After washing 4 times with TBS-T, the membrane was reacted with HRP-conjugated secondary antibody in TBS-T containing 1\% skim milk for $1 \mathrm{~h}$ at room temperature. After washing 2 times, immunoreactive proteins were detected with ECL Plus (GE Healthcare). Serum from the patient (with written informed consent) was taken by the medical doctor (S.K.), and stored at $-30^{\circ} \mathrm{C}$ to be used as a primary antibody. The serum from a patient who was assumed to not have had any contact with C. yamaguchii was used as a negative control. HRP-conjugated goat anti-human IgG (1:50,000 dilutions, polyclonal; Zymed ${ }^{\circledR} /$ Invitrogen $^{\mathrm{TM}}$; Thermo Fisher Scientific), HRP-conjugated mouse anti-human $\operatorname{IgG}_{1}(1: 10,000$ dilutions, monoclonal; Zymed/Invitrogen), HRP-conjugated mouse anti-human $\operatorname{IgG}_{4}(1: 10,000$ dilutions, monoclonal; Zymed/Invitrogen) and HRP-conjugated goat anti-human IgE (1:20,000 dilutions, polyclonal; Kirkegaard \& Perry Lab., Gaithersburg, Wash., USA) were used as secondary antibodies.

\section{Glycosylation of IgG-Binding Allergen Protein}

The NCS extracts were deglycosylated to examine whether they contained amino acid-linked sugar residues of $\mathrm{N}$-linked or $\mathrm{O}$-linked oligosaccharides. The extent of deglycosylation was assessed by mobility on SDS-PAGE using the enzymatic protein deglycosylation kit (Sigma-Aldrich, St. Louis, Mo., USA) according to the manufacturer's instructions. $N$-linked sugars were removed by digestion with the enzyme PNGase F [peptide-N4-(acetyl- $\beta$-glucosaminyl)asparagine amidase] and $O$-linked sugars were removed by using 

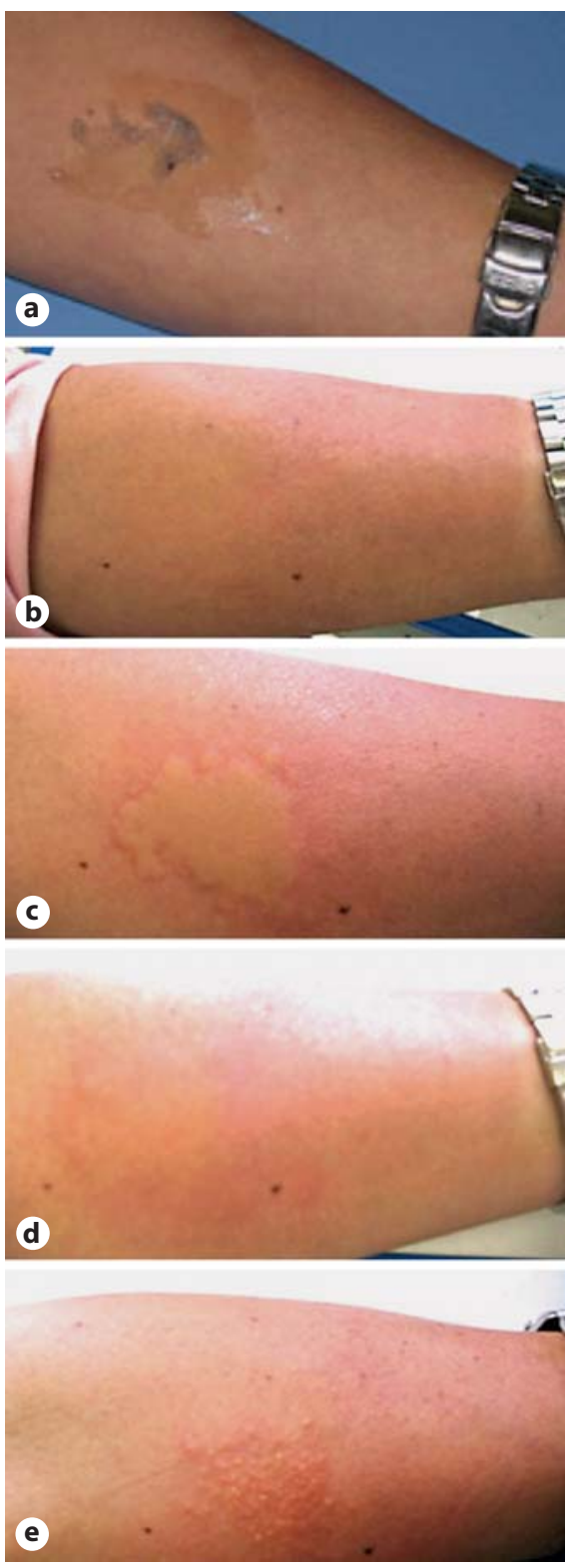

Fig. 2. Sequential changes in an acute lesion from a C. yamaguchii sting. a C. yamaguchii sting at the clinic. b The tentacle is applied and the skin is examined 15 min later (c), 1 h later (d) and $24 \mathrm{~h}$ later (e).

the enzymes, glycosidase (endo- $\alpha-N$-acetylgalactosaminidase) and $\alpha-2(3,6,8,9)$-neuraminidase, respectively.

\section{Skin-Prick Test}

The doctor put a drop each of solutions containing intact and thermally deactivated CqTX-A on the patient's forearm using a sterilized needle, and then pricked the skin to allow the toxin to enter beneath the epidermis for $20 \mathrm{~min}$ in order for a reaction to appear. PBS was used as a negative control.

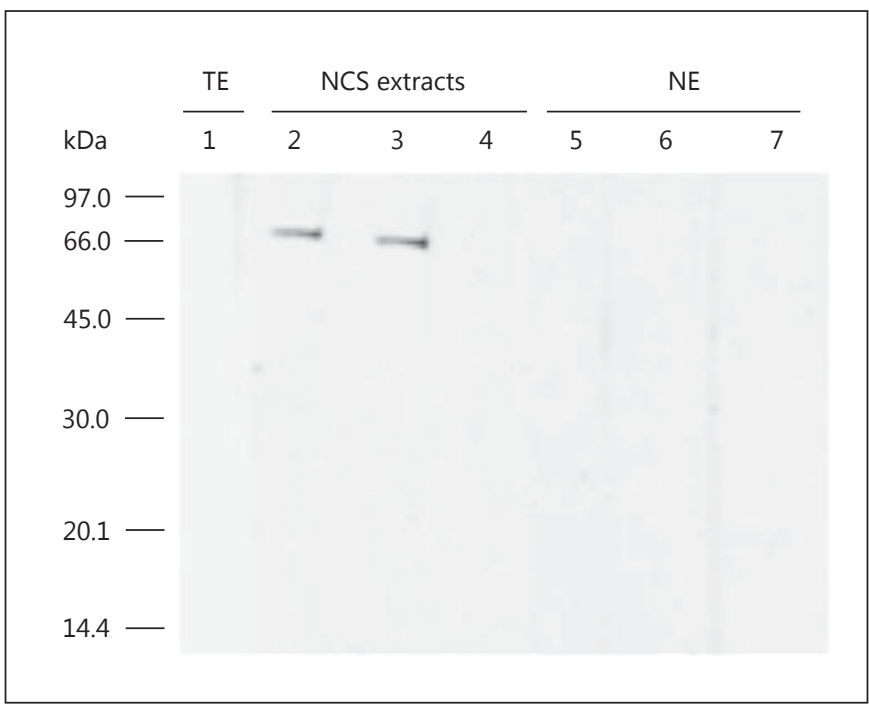

Fig. 3. Comprehensive examination of reactive protein in C. yamaguchii with patient sera. Tentacle extracts (TE, lane 1), NCS extracts (lanes 2-4) and nematocyst extracts (NE, lanes 5-7) from $C$. yamaguchii were subjected to SDS-PAGE followed by Western blotting. IgG-binding protein was detected with primary antibodies followed by HRP-conjugated goat anti-human IgG: patient serum after sting (lanes 1,2 and 5), patient serum before the sting (lanes 3 and 6) and negative control serum (lanes 4 and 7). About $66 \mathrm{kDa}$ of IgG-binding protein was detected in lanes 2 and 3.

\section{Lymphocyte Transformation Test}

A lymphocyte transformation test was done using heparinized blood followed by the isolation culture. The stimulation by the tentacle extracts was monitored by means of ${ }^{3} \mathrm{H}$-thymidine incorporation.

\section{Results}

\section{Skin Eruption from the Jellyfish Stings}

A 43-year-old male patient, who had a history of repeated sting injury by jellyfish over several years, visited our health clinic for skin eruptions after being stung by jellyfish during maritime fieldwork in the Okinawa islands. His immunoglobulin profiles were IgE: $460 \mathrm{IU} / \mathrm{ml}$ (high), IgG: $927 \mathrm{mg} / \mathrm{dl}$, IgA: $269 \mathrm{mg} / \mathrm{dl}$ and IgM: $40 \mathrm{mg} /$ dl. He was sensitized to the house-dust mite, Dermatophagoides pteronyssinus. His C-reactive protein was negative, white blood cell count $4,600 / \mu \mathrm{l}$ and hemoglobin $14.3 \mathrm{~g} / \mathrm{dl}$. The pain and papular eruption appeared immediately after the sting injury and the prick application, likely indicating a toxic reaction (fig. 2a, b). Erythema, wheal formation, induration and itching followed 


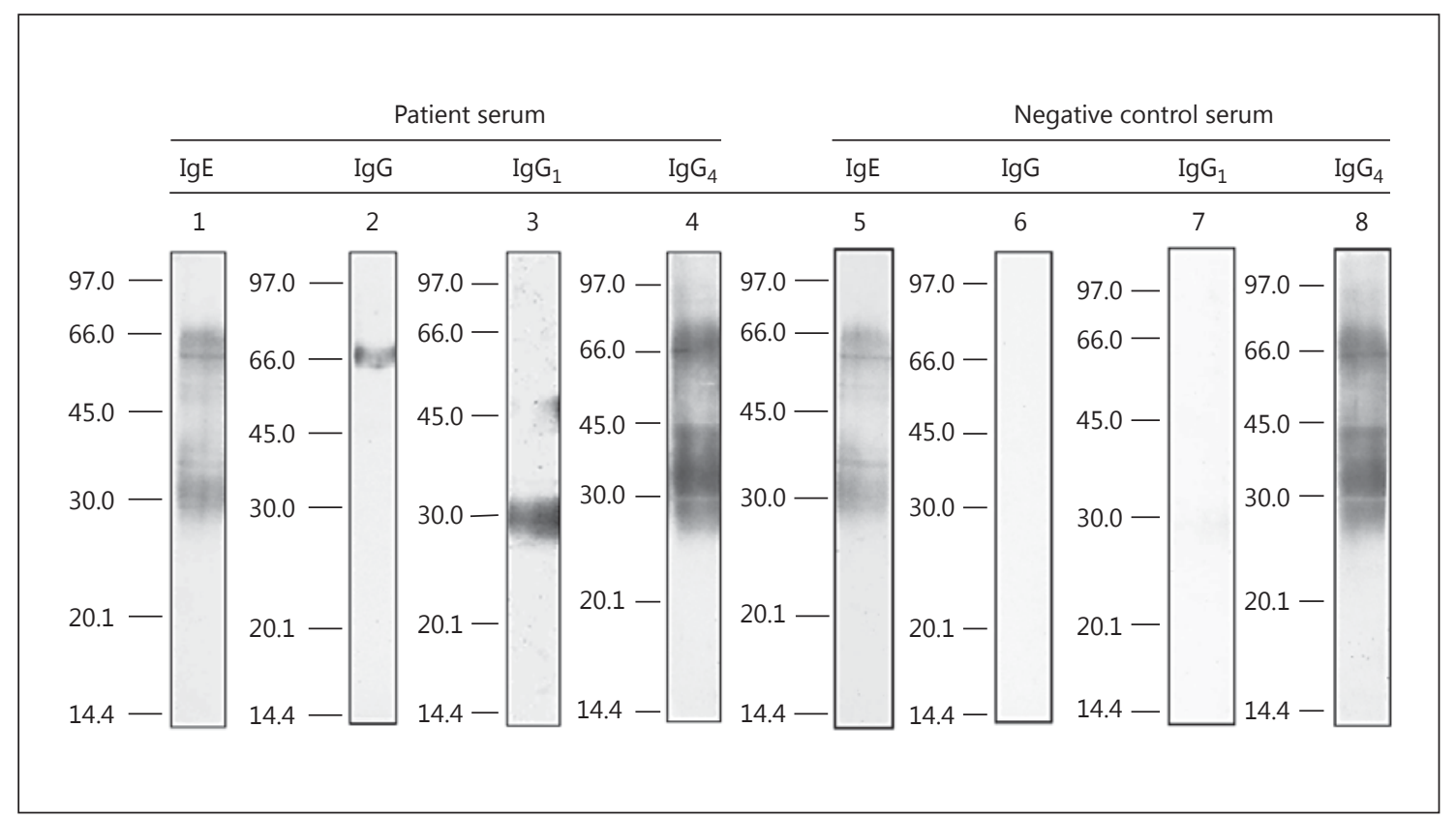

Fig. 4. Reactive proteins in NCS extracts. The extracts were subjected to SDS-PAGE followed by Western blotting with the patient's serum after the sting and negative control serum, and secondary antibodies: HRP-conjugated goat anti-human IgE (lanes 1 and 5), HRP-conjugated goat anti-human IgG (lanes 2 and 6), HRP-conjugated mouse anti-human $\operatorname{IgG}_{1}$ (lanes 3 and 7) and HRP-conjugated mouse anti-human $\operatorname{IgG}_{4}$ (lanes 4 and 8). When using the patient's serum, a band of $66 \mathrm{kDa}$ was detected with IgE, IgG and $\operatorname{IgG}_{4}$ (lanes 1, 2 and 4) and a band of $30 \mathrm{kDa}$ was detected with $\mathrm{IgE}, \mathrm{IgG}_{1}$ and $\operatorname{IgG}_{4}$ (lanes 1,3 and 4 ). When using the negative control serum, faint bands of $66-$ and $30-\mathrm{kDa}$ proteins were detected in $\operatorname{IgE}$ and $\operatorname{IgG}_{4}$ (lanes 5 and 8 ) and no band was detected in IgG and $\operatorname{IgG}_{1}$ (lanes 6 and 7).
15 min later as allergic reactions (fig. 2c). One hour later, the erythema and wheal persisted and fused with each other, in spite of a decrease in pain and the hot sensation (fig. 2d). After $24 \mathrm{~h}$, the papules and pigmentation were still conspicuous (fig. 2e). The skin eruption subsided gradually after this, but the erythema relapsed after 7 days.

\section{Comprehensive Examination of the Reactive Protein from C. yamaguchii}

For detection of IgG-binding protein molecules in $C$. yamaguchii (fig. 1a), each sample, i.e. the extracts of the tentacle, the nematocyst and the NCS, was subjected to Western blotting with the patient's serum and HRP-conjugated goat anti-human IgG. A protein with a molecular weight of $66 \mathrm{kDa}$ was detected in the NCS extracts (fig. 3: lanes 2,3$)$. This protein was reactive with the sera of the same patient before and after the stings. In the tentacle and nematocyst extracts, no IgG-binding protein bands were detected (fig. 3: lanes 1, 5-7). It was therefore hypothesized that the $66-\mathrm{kDa}$ protein in the NCS extracts is a reactive protein.

Identification of Specific Allergens in C. yamaguchii

\section{Isotype Specificity of the Reactive Protein in the NCS} Extracts

To determine isotype specificity to the protein, the NCS extracts were subjected to SDS-PAGE followed by Western blotting with human $\operatorname{IgE}, \mathrm{IgG}, \operatorname{IgG}_{1}$ and $\operatorname{IgG}_{4}$. The 66 - and $30-\mathrm{kD}$ a proteins reacted with HRP-conjugated goat anti-human IgE (fig. 4: lane 1). The $66-\mathrm{kDa}$ protein reacted with HRP-conjugated goat anti-human IgG (fig. 4: lane 2) similarly to in figure 3 . The $30-\mathrm{kDa}$ protein reacted with HRP-conjugated mouse anti-human $\operatorname{IgG}_{1}$ (fig. 4: lane 3). The 66- and 30-kDa proteins also reacted with $\mathrm{HRP}$-conjugated mouse anti-human $\mathrm{IgG}_{4}$ (fig. 4 : lane 4 ). The $30-\mathrm{kDa}$ protein was not detected under the nonreducing condition. In the serum from the negative control, faint bands of the 66- and $30-\mathrm{kDa}$ proteins were detected in IgE and $\mathrm{IgG}_{4}$, but no band was detected in $\operatorname{IgG}_{1}$ (fig. 4: lanes 5-8).

Characterization of the Protein in the NCS Extracts by Ion-Exchange Chromatography

To characterize IgG-binding protein, NCS extracts were applied to cation-exchange HPLC (Hitrap-CM) and 


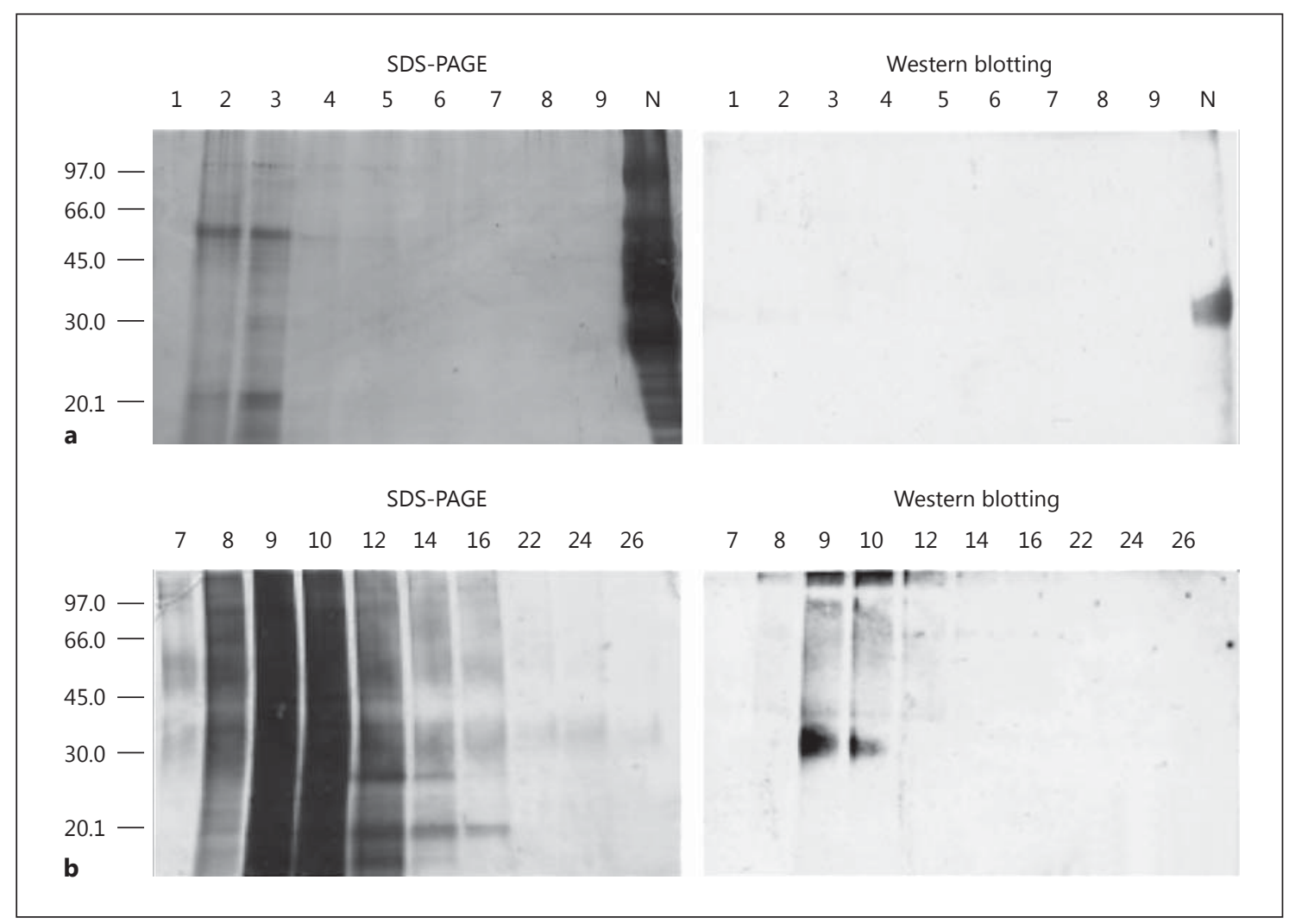

Fig. 5. Characterization of IgG-reactive protein on ion-exchange chromatography. NCS extracts were applied to cation-exchange HPLC (a; Hitrap-CM) and anion-exchange HPLC (b; HitrapDEAE). Fractions after Hitrap-CM (fractions 1-9 and the nonabsorbed fraction) and after Hitrap-DEAE (fractions 7-26) were subjected to SDS-PAGE. These fractions were analyzed by Western blotting with the patient's serum after the sting and HRP-con-

anion-exchange HPLC (Hitrap-DEAE). On Hitrap-CM chromatography, we found that the $30-\mathrm{kDa}$ protein in the nonabsorbed fraction was detected by Western blot with the patient's serum and HRP-conjugated goat anti-human IgG (fig. 5a). Similary, on Hitrap-DEAE chromatography, the $30-\mathrm{kDa}$ protein was detected in the absorbed fraction (fig. 5b: lanes 9, 10). The $66-\mathrm{kDa}$ protein was not detected in any fractions. These results revealed that the IgG-binding protein was an acidic protein.

\section{Glycosylation of Specific IgG-Binding Protein}

To determine the glycosylation of IgG-binding protein in the NCS extracts, we analyzed the mobility shifts of IgG-binding protein by digestion with PNGase F, O-glycosidase and $\alpha-2(3,6,8,9)$-neuraminidase. The validity of these enzymes was confirmed using bovine fetuin, which contains sialylated $\mathrm{N}$-linked and $\mathrm{O}$-linked oligosaccha- jugated goat anti-human IgG. An IgG-binding allergen was detected at $30 \mathrm{kDa}$ in the Hitrap-CM nonabsorbed fraction and in the Hitrap-DEAE fractions 9 and 10. Major proteins of NCS extracts were detected in the Hitrap-DEAE fractions 8-16 and in the Hitrap-CM nonabsorbed fraction by silver-staining SDS-PAGE. $\mathrm{N}=$ Nonabsorbed fraction. rides (data not shown). Samples without enzyme digestion were used as a control. Samples and control were incubated for $3 \mathrm{~h}$ at $37^{\circ} \mathrm{C}$, and their mobility shifts were then analyzed by SDS-PAGE. PNGase F decreased the protein into a smaller amount of molecular weight (fig. 6 : lanes $1,2,4)$, whereas $O$-glycosidaseand $\alpha-2(3,6,8,9)$-neuraminidase did not affect the mobility of the allergen when compared with the control (fig. 6: lanes $\mathrm{C}, 3$ ). These results indicated that the protein was asparagine residuecoupled $\mathrm{N}$-linked glycoprotein and that the epitope resided not in the glycoside but in the protein fraction.

\section{Identification of the Allergen in the Nematocyst Extracts}

The nematocyst extracts were subjected to Western blotting with HRP-conjugated goat anti-human IgE, HRP-conjugated goat anti-human IgG, HRP-conjugated 


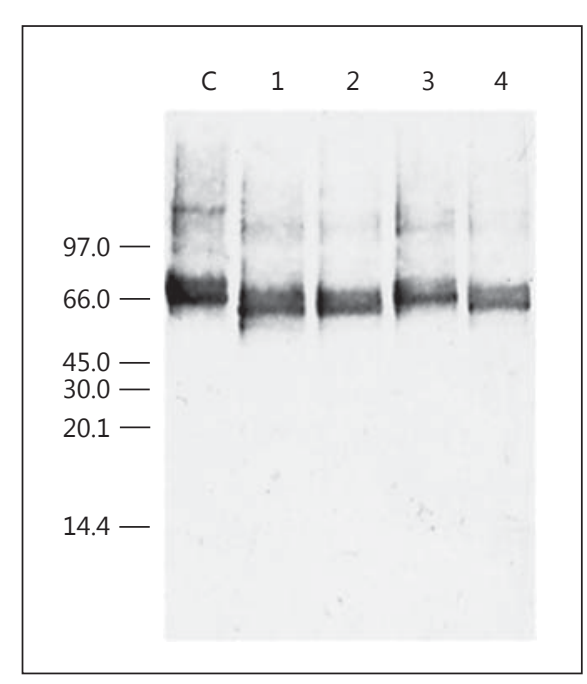

Fig. 6. Detection of reactive protein in NCS extracts after deglycosylation. NCS extracts were digested with PNGase F (lane 1), PNGase F and $\alpha$-2 $(3,6,8,9)$-neuraminidase (lane 2$), O$-glycosidase and $\alpha-2(3,6,8,9)$-neuraminidase (lane 3$)$, and PNGase $\mathrm{F}$ and $O$ glycosidase and $\alpha$-2 $(3,6,8,9)$-neuraminidase (lane 4$)$. Nondeglycosylated NCS extracts (lane C) and deglycosylated samples (lane 1-4) were subjected to SDS-PAGE and Western blotting with the patient's serum and HRP-conjugated goat anti-human IgG. Similar band shifts were detected in lanes 1, 2 and 4 from nondeglycosylated NCS extracts (lane C vs. lanes 1, 2 and 4). The band in lane 3 did not shift from the position of the nondeglycosylated NCS extracts.

mouse anti-human $\mathrm{IgG}_{1}$ and $\mathrm{HRP}$-conjugated mouse anti-human $\mathrm{IgG}_{4}$. The result shows that these extracts had a main protein around $45 \mathrm{kDa}$ and a minor protein in 43 $\mathrm{kDa}$ (fig. 7: left). The main protein reacted with IgE and $\mathrm{IgG}_{4}$ (fig. 7: lanes 1, 3). Similarly, the minor protein (43 $\mathrm{kDa}$ ) reacted with $\operatorname{IgE}$ (fig. 7: lane 1). We did not find any bands that reacted with $\operatorname{IgG}_{1}$ (fig. 7: lane 2). In the negative control serum, no bands were detected in $\operatorname{IgG}_{1}$ and a faint band of $45-\mathrm{kD}$ a protein was detected in $\mathrm{IgE}$ and $\operatorname{IgG}_{4}$ (fig. 7: lanes 4-6).

\section{Antigen-Antibody Reaction of CqTX-A with Human IgE}

From the above findings (fig. 7), we assumed that the IgE-binding protein of the nematocyst extracts was the main protein toxin CqTX-A, identified in a previous study [14]. We isolated CqTX-A (19.7 mg) based on the hemolytic activity (122,880 units) and detected it in SDSPAGE (45 kDa; fig. 8: left). The results of Western blotting showed that IgE-binding CqTX-A was detected at the position identical to a major band of nematocyst extracts (fig. 8: lane 1 vs. lane 2). In addition, CqTX-A also reacted with $\mathrm{IgG}_{4}$ (fig. 8: lane 3). No band was detected in anti-IgE (fig. 8: lane 4) or anti-IgG (fig. 8: lane 5) in the serum from the negative control. In the skin-prick test, both intact and thermally deactivated CqTX-A caused erythematous skin eruption in the patient; the mean diameters of induration and erythema were $8 \times 5$ and $11 \times 8 \mathrm{~mm}$ for intact CqTX-A, $6 \times 6$ and $12 \times 18 \mathrm{~mm}$ for thermally deactivated CqTX-A and $5 \times 4$ and $6 \times$ $6 \mathrm{~mm}$ for PBS, respectively. Thus, the IgE epitope of CqTX-A is a heat-stable protein and it does not change its conformation, allowing IgE to recognize the molecule after heating.

\section{Discussion}

Common signs of jellyfish stings include pain, skin eruptions, itching, swelling or numbness. The stings of many species of box jellyfish, i.e. C. yamaguchii, C. fleckeri and C. barnesi and also of the hydrozoan jellyfish P. physalis can be fatal $[2,3]$.

In this study, we comprehensively investigated the specific allergens in the box jellyfish C. yamaguchii, which was separated into 3 parts, the tentacles, the nematocyst and the NCS, in order to study the allergen (fig. 1a). We detected an IgG-binding protein and an IgE-binding allergen in C. yamaguchii.

The major protein toxin with a molecular weight of 45 $\mathrm{kDa}, \mathrm{CqTX}-\mathrm{A}$, in the nematocyst, was found to be an IgEand an $\mathrm{IgG}_{4}$-binding allergen. Nagai et al. [14] reported that they isolated this main protein toxin of C. yamaguchii from the venom obtained from the nematocyst and also deduced its amino acid sequence. They also isolated Carybdea arborifera (formerly Carybdea alata) protein toxins (CaTX-A, CaTX-B) and Carybdea brevipedalia (formerly Carybdea rastoni) protein toxins (CrTX-A, CrTX-B) and designated them the 'jellyfish toxin family' $[21,22]$. C. fleckeri protein toxins (CfTX-1, CfTX-2) show 89 and $72 \%$ sequence homology to CqTX-A by amino acid sequence alignment [23]. These box jellyfishes are well known to cause injury to fishermen, fisherwomen, scuba divers, surfers and sea-bathers in Japan, Hawaii and Australia.

Dermatitis caused by jellyfish stings can be characterized as 3 types of immune reaction, i.e. immediate allergic, late-phase reaction and relapsing allergic response, which correspond to clinical reactions [6]. The pathogenesis caused by the jellyfish stings includes at least both jellyfish toxic effects and a significant immediate allergic response. Intact CqTX-As and thermally deactivated 
Fig. 7. Detection of reactive protein in nematocyst extracts by Western blotting. Nematocyst extracts were subjected to SDS-PAGE followed by silver-staining or Western blot with the patient's serum and negative control serum, and various secondary antibodies: HRP-conjugated goat anti-human IgE (lanes 1 and 4), HRP-conjugated mouse anti-human $\operatorname{IgG}_{1}$ (lanes 2 and 5) and HRP-conjugated mouse antihuman $\operatorname{IgG}_{4}$ (lanes 3 and 6). A major band of $45-\mathrm{kDa}$ protein was observed in SDSPAGE and reacted with human IgE and $\mathrm{IgG}_{4}$ (lanes 1 and 3). A minor band of 43 $\mathrm{kDa}$ was observed in SDS-PAGE and each reacted with IgE (lane 1 ). No protein reaction with $\operatorname{IgG}_{1}$ was detected (lane 2 ). When using the negative control serum, no band was detected with $\operatorname{IgG}_{1}$ and a faint band of $45-\mathrm{kDa}$ protein was detected with $\operatorname{IgE}$ and $\mathrm{IgG}_{4}$.

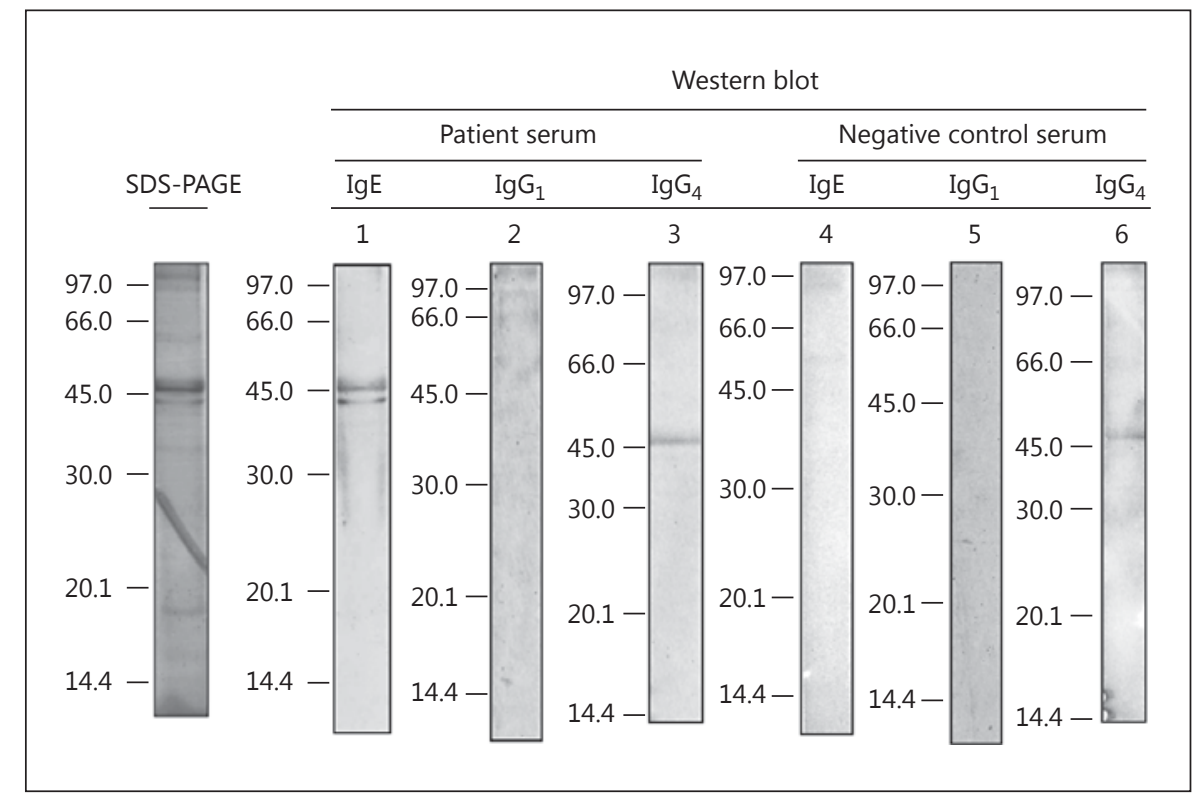

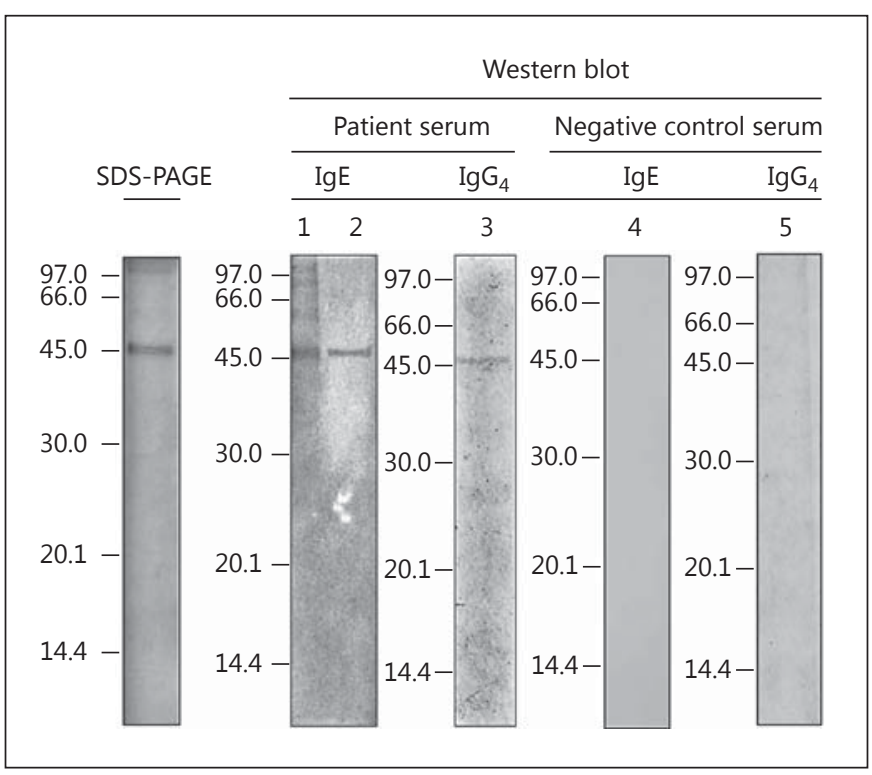

Fig. 8. Detection of the allergen reactive with CqTX-A. The purified protein toxin of C. yamaguchii CqTX-A was subjected to SDSPAGE, followed by silver-staining or Western blot with the patient's serum (lanes 1-3) and negative control serum (lanes 4 and 5) and various secondary antibodies. Left: CqTX-A was detected at $45 \mathrm{kDa}$ on SDS-PAGE. Lane 1: nematocyst extracts with HRP-conjugated goat anti-human IgE. Lanes 2 and 4: CqTX-A with HRP-conjugated goat anti-human IgE. Lanes 3 and 5: CqTX-A with HRP-conjugated mouse anti-human $\operatorname{IgG}_{4}$. The bands of CqTX-A which reacted with $\mathrm{IgE}$ and $\mathrm{IgG}_{4}$ on Western blot were detected at a position identical to a major band of nematocyst extracts (SDS-PAGE and lane 1 vs. lanes 2 and 3). With the negative control serum, no band was detected with anti-IgE (lane 4) or with anti-IgG (lane 5).
CqTX-As were used as allergens for the prick test. The test showed only an immediate allergic reaction, i.e. itching and erythema. The lymphocyte transformation test on the tentacle extracts showed a stimulation index of 0.87 (subnormal range) compared with $>139$ with phytohemagglutinin. This result indicated the absence of a $\mathrm{T}$ cell-mediated reaction. Taken together, it was shown that CqTX-A caused a mixed venom immune reaction, although the precise mechanisms remain unknown. In particular, it is not known whether $\operatorname{IgG}\left(\operatorname{IgG}_{4}\right)$ is involved in the late-phase reaction or if it reflects the repeated sting injury $[24,25]$. IgG $\mathrm{I}_{1}$ has been found to be involved in systemic anaphylaxis in a mouse model [26] and in the late asthmatic response in an epidemiological survey [27]. It has also been recognized in canine mast cell activations [25]. The pathogenesis caused by the venom from wasp and bee stings and that of aspergillosis or anisakis disease cannot be explained by allergic or toxic reactions alone. In fact, both these types of reactions occur simultaneously or sequentially and modify the symptoms and signs in the subacute and chronic phase. Bee venom contains melittin, histamine and phospholipase A, causing toxic effects along with an IgE reaction in the second sensitization [28]. The clinical progression of allergic bronchopulmonary aspergillosis and aspergilloma, however, is interwoven, and could worsen to chronic pulmonary aspergillosis in the case of infection by fungi of the genus Aspergillus.
Horiike/Nagai/Kitani 
The IgG- and $\operatorname{IgG}_{1}$-binding proteins that we detected were a 66 - and a $30-\mathrm{kDa}$ protein from the NCS; the 66$\mathrm{kDa}$ protein possibly resulted from the dimerization of the $30-\mathrm{kDa}$ protein. It has been suggested that a minicollagen is the main component of the NCS [29], so this glycoprotein reacting with IgG might be a minicollagen in the nematocyst. Nematocysts are toxin-containing capsules with apparatus for catching prey, and are located in the jellyfish tentacles (fig. 1b). They have a 'barb' in the spine and discharged toxins can reside in a victim's skin tissue for a long time [13]. Thus, a minicollagen in the wall of the nematocyst could cause $\operatorname{IgG}_{1}$ and IgG reactions that trigger anaphylaxis, late-phase allergic reactions or a delayed hypersensitive reaction.

First-aid for jellyfish stings includes: (1) the inhibition of discharge of unfired adherent nematocysts by applying vinegar, (2) the removal of the tentacle and (3) applying ice to the skin to control the pain. Victims must be treated depending on their symptoms and the size of the affected area. Current clinical treatment is palliative and according to symptoms, i.e. with topical steroids and anti-inflammatory drugs [30]. To date, no effective treatment based on the evidence exists for stings. Recently, the Cochrane Collaboration reviewed interventions for stings of both adults and children, and did not produce any significant evidence for the efficacy of applying vinegar or ice [31].

In 1902, Portier and Richet [32], who had started studies on cnidarians, injected dogs with sea anemone venom twice, and expected a protective immune response (or prophylaxis), but found the opposite: 'the hypersensitive reaction anaphylaxis'. From an occupational and hygienic point of view, fishery employees suffer anaphylaxis and allergic symptoms from cnidarian injuries and beekeepers can become allergic to bee stings. In the case of beekeepers, hyposensitization therapy using allergens has already been developed as a preventive method [33]. An- tivenom antibody was developed against box jellyfish venom and has been used over the last 30 years with limited efficacy [34].

It is plausible that CqTX-A has cross-reactivity with CaTX-A and CaTX-B, CrTX-A and CrTX-B and CfTX-1 and CfTX-2 because of their amino acid sequence similarities. Nagai et al. [35] and Iguchi et al. [36] managed to isolate other cnidarian protein toxins, i.e. in the sea anemone Phyllodiscus semoni and the fire coral Millepora sp.; these cause a similar immune reaction in the skin. If we can reveal the IgG epitope in cnidarian nematocyst minicollagen or the IgE epitope in the family of versatile toxins, more effective treatments will be made possible, such as hyposensitization therapy for relapsing allergic reactions and specific anaphylaxis (venom immunotherapy) from cnidarian injury for marine professionals and tourists.

In our study, we found a 45-kDa IgE-binding allergen to CqTX-A and 66- and 30-kDa IgG-binding proteins in the NCS extracts. The detection of these proteins does, in part, explain the combined immediate allergic-toxic and persistent inflammatory response; this will hopefully lead to the development of specific and effective clinical applications for marine-sting dermatitis.

\section{Acknowledgements}

The authors thank Mio Arai, Tokyo University of Marine Science and Technology, for conducting the experiments, and Dr. Naomasa Oshiro and Ms. Setsuko Iwanaga, members of the Okinawa Prefectural Institute of Health and Environment, for photography and sample collection.

\section{Disclosure Statement}

The authors declare no conflicts of interest.

\section{References}

1 Lewis C, Bentlage B: Clarifying the identity of the Japanese Habu-kurage, Chironex yamaguchii, sp. nov. (Cnidaria: Cubozoa: Chirodropida). Zootaxa 2009;2030:59-65.

2 Williams J, Burnett J: Clinical toxicology of marine coelenterate injuries; in Meier J, White J (eds): Handbook of Clinical Toxicology of Animal Venoms and Poisons. Boca Raton, CRC Press, 1995, pp 89-133.

3 Fenner PJ, Hadok JC: Fatal envenomation by jellyfish causing Irukandji syndrome. Med J Aust 2002;177:362-363.

\footnotetext{
4 Boulware DR: A randomized, controlled field trial for the prevention of jellyfish stings with a topical sting inhibitor. J Travel Med 2006; 13:166-171.

5 Annual Report of Okinawa Prefectural Institute of Health and Environment (in Japanese). Okinawa, 2014. http://www.eikankenokinawa.jp/seitaiG/kiken/pdf/H25report.pdf (last accessed January 10, 2015).
}

Identification of Specific Allergens in C. yamaguchii
Int Arch Allergy Immunol 2015;167:73-82 DOI: $10.1159 / 000434721$ 
6 Loredana Asztalos M, Rubin AI, Elenitsas R, Groft MacFarlane C, Castelo-Soccio L: Recurrent dermatitis and dermal hypersensitivity following a jellyfish sting: a case report and review of literature. Pediatr Dermatol 2014; 31:217-219.

7 Fisher AA: Toxic and allergic cutaneous reactions to jellyfish with special reference to delayed reactions. Cutis 1987;40:303-305.

8 Tibballs J, Yanagihara AA, Turner HC, Winkel K: Immunological and toxinological responses to jellyfish stings. Inflamm Allergy Drug Targets 2011;10:438-446.

9 Kass-Simon G, Scappaticci AA: The behavioral and developmental physiology of nematocysts. Can J Zool 2002;80:1772-1794.

10 Nagai H: Recent progress in jellyfish toxin study. J Health Sci 2003;49:337-340.

11 Özbek S, Pokidysheva E, Schwager M, Schulthess T, Tariq N, Barth D, Milbradt AG, Moroder L, Engel J, Holstein TW: The glycoprotein NOWA and minicollagens are part of a disulfide-linked polymer that forms the cnidarian nematocyst wall. J Biol Chem 2004; 279:52016-52023.

$\checkmark 12$ Meier S, Häussinger D, Pokidysheva E, Bächinger HP, Grzesiek S: Determination of a high-precision NMR structure of the minicollagen cysteine-rich domain from Hydra and characterization of its disulfide bond formation. FEBS Lett 2004;569:112-116.

13 Özbek S, Balasubramanian PG, Holstein TW: Cnidocyst structure and the biomechanics of discharge. Toxicon 2009;54:1038-1045.

-14 Nagai H, Takuwa-Kuroda K, Nakao M, Oshiro N, Iwanaga S, Nakajima T: A novel toxin from the deadly box jellyfish (sea wasp, Habu-kurage) Chiropsalmus quadrigatus. Biosci Biotech Biochem 2002;66:97-102.

15 Nagamori T: Biochemical study on the proteins including toxins from the nematocysts of Chiropsalmus quadrigatus (in Japanese); Master's thesis, Tokyo University of Marine Science and Technology, Tokyo, 2007.
16 Tanaka K, Kondo Y, Inuo C, Nakajima Y, Tsuge I, Doi S, Urisu A: Allergen analysis of sea urchin roe using sera from five patients. Int Arch Allergy Immunol 2014;164:222-227.

17 Onizuka R, Kamiya H, Muramoto K, Goto R, Inoue K, Kumamoto K, Nakajima Y, Iida S, Ishigami F: Purification of the major allergen of red soft coral (Dendronephthya nipponica). Int Arch Allergy Immunol 2001;125:135-143.

18 Burnett JW: Human injuries following jellyfish stings. Md Med J 1992;41:509-513.

19 Carrette T, Seymour J: A rapid and repeatable method for venom extraction from Cubozoan nematocysts. Toxicon 2004;44:135-139.

20 Kawabata T, Lindsay DJ, Kitamura M, Konishi S, Nishikawa J, Nishida S, Kamio M, Nagai $\mathrm{H}$ : Evaluation of the bioactivities of water-soluble extracts from twelve deep-sea jellyfish species. Fish Sci 2013;79:487-494.

21 Nagai H, Takuwa K, Nakao M, Sakamoto B, Crow GL, Nakajima T: Novel proteinaceous toxins from the box jellyfish (sea wasp) $\mathrm{Ca}$ rybdea rastoni. Biochem Biophys Res Commun 2000;275:582-588.

-22 Nagai H, Takuwa K, Nakao M, Sakamoto B, Crow GL, Nakajima T: Isolation and characterization of a novel protein toxin from the Hawaiian box jellyfish (sea wasp) Carybdea alata. Biochem Biophys Res Commun 2000; 275:589-594.

-23 Brinkman D, Burnell J: Identification, cloning and sequencing of two major venom proteins from the box jellyfish, Chironex fleckeri. Toxicon 2007; 50:850-860.

24 Aalberse RC, Stapel SO, Schuurman J, Rispens $\mathrm{T}$ : Immunoglobulin $\mathrm{G}_{4}$ : an odd antibody. Clin Exp Allergy 2009;39:469-477.

25 Sato Y, Teshima R, Nakamura R, Takagi K, Sasaki N, Sawada J, Kitani S: Canine mast cell activation via human $\operatorname{IgG}_{1}$ and $\operatorname{IgG}_{4}$. Int Arch Allergy Immunol 2004;135:154-160.

-26 Miyajima I, Dombrowicz D, Martin TR, Ravetch J V, Kinet JP, Galli SJ: Systemic anaphylaxis in the mouse can be mediated largely through $\mathrm{IgG}_{1}$ and $\mathrm{Fc} \gamma \mathrm{RIII}$. Assessment of the cardiopulmonary changes, mast cell degranulation, and death associated with active or IgE- or $\operatorname{IgG}_{1}$-dependent passive anaphylaxis. J Clin Invest 1997;99:901-914.
27 Ito K, Kudo K, Okudaira H, Yoshinoya S, Morita Y, Nakagawa T, Akiyama K, Urata C, Hayakawa T, Ohta K,Nakada S, Horiuchi T, Takizawa H, Shoji S, Ishii A, Kitani S, Haida M, Yamashita N, Honda Z, Miyamoto T: $\operatorname{IgG}_{1}$ antibodies to house dust mite (Dermatophagoides farinae) and late asthmatic response. Int Arch Allergy Appl Immunol 1986;81:6974.

28 Nishikawa H, Kitani S: Gangliosides inhibit bee venom melittin cytotoxicity but not phospholipase $\mathrm{A}_{2}$-induced degranulation in mast cells. Toxicol Appl Pharmacol 2011;252:228236.

29 Kurz EM, Holstein TW, Petri BM, Engel J, David CN: Mini-collagens in hydra nematocytes. J Cell Biol 1991;115:1159-1169.

30 Meier J, White J: Handbook of Clinical Toxicology of Animal Venoms and Poisons. CRC Press, 1995

31 Li L, McGee RG, Isbister G, Webster AC: Interventions for the symptoms and signs resulting from jellyfish stings. Cochrane Database Syst Rev 2013;12:CD009688.

32 Portier PJ, Richet CR: De l'action anaphylactique de certains venins. Compt Rend Soc Biol (Paris) 1902;54:170-172.

33 Golden DBK, Schwartz HJ: Guidelines for venom immunotherapy. J Allergy Clin Immunol 1986;77:727-728.

34 Isbister GK: Antivenom efficacy or effectiveness: the Australian experience. Toxicology 2010;268:148-154.

-35 Nagai H, Oshiro N, Takuwa-Kuroda K, Iwanaga S, Nozaki M, Nakajima T: Novel proteinaceous toxins from the nematocyst venom of the Okinawan sea anemone Phyllodiscus semoni Kwietniewski. Biochem Biophys Res Commun 2002;294:760-763.

36 Iguchi A, Iwanaga S, Nagai H: Isolation and characterization of a novel protein toxin from fire coral. Biochem Biophys Res Commun 2008;365:107-112. 